\title{
HUBUNGAN POLA ASUH ORANG TUA BEKERJA DENGAN PERKEMBANGAN ANAK USIA PRASEKOLAH (4 - 5 TAHUN) DI TK GMIM BUKIT MORIA MALALAYANG
}

\author{
Rina Kundre \\ Yolanda B Bataha \\ Program Studi Ilmu Keperawatan Fakultas Kedokteran \\ Universitas Sam Ratulangi \\ Email : rina_kundre@yahoo.com
}

\begin{abstract}
Parenting which applied by parents have an important role to educate them and asreflection aboutparents attitudes and behavior in child development, aims that children can grow and develop optimally. The Purpose of this study is to know the relationship between Working parent's Parenting with Preschool Children's development (4 - 5 years old) at TK GMIM Bukit Moria Malalayang. Method of this study uses descriptive research design with a cross-sectional approach. Sample of this study consisted of 33 children and 33 parents, using saturated sample techniques. Results of this study, out of 33 children mostlyhave dubious developments (45.5\%) parenting that use in the family is good parenting (81.8\%), using the sperman-rank test shows the interpretation of the correlation coefficient $r$-value was 0,4 . the strength of the relationship is moderate and p-value was 0.021. significance level of alfa (a) 0.05. it was found that p-value was 0.021 smaller than significant value of 0.05.Conclusion of this study, There is a significant Relationship between Working parent's Parenting with Preschool Children's development (4 - 5 years old) at TK GMIM Bukit Moria Malalayang. Suggestions for parents can apply a good parenting to children.
\end{abstract}

Keywords: Parenting, Children Development, Preschool

\begin{abstract}
Abstrak: Pola asuh yang diterapkan oleh orang tua berperan penting dalam mendidik anak yang merupakan gambaran tentang sikap dan perilaku orang tua dalam perkembangan anak bertujuan agar anak dapat tumbuh serta berkembang secara optimal. Tujuan penelitian untuk mengetahui hubungan pola asuh orang tua bekerja dengan perkembangan anak usia prasekolah (4 - 5 tahun) di TK GMIM Bukit Moria Malalayang. Metode penelitian ini menggunakan desain penelitian deskriptif korelasi dengan pendekatan cross-sectional. Sampel terdiri dari 33 orang anak dan 33 orang tua dengan menggunakan teknik sampel jenuh. Hasil dari 33 anak yang di teliti sebagian besar perkembangan meragukan $(45,5 \%)$ didapatkan bahwa pola asuh yang diterapkan dalam keluarga adalah pola asuh baik $(81,8 \%)$, dengan menggunakan uji sperman-rank menunjukan interpretasi koefisien korelasi nilai $r$ adalah 0,4 , sehingga kekuatan hubungan sedang dan nilai $p$ adalah 0,021 . Tingkat kemaknaan alfa $(a)$ yang digunakan yaitu: 0,05 . Jadi $p=0,021<0,05$. Kesimpulan terdapat hubungan yang signifikan antara pola asuh orang tua bekerja dengan perkembangan anak usia prasekolah (4 - 5 tahun) di TK GMIM Bukit Moria Malalayang. Saran diharapkan orang tua dapat menerapkan pola asuh yang baik sesuai dengan usia anak.
\end{abstract}

Kata Kunci : Pola Asuh, Perkembangan Anak, Usia Prasekolah 


\section{PENDAHULUAN}

Makhluk hidup berkembang sesuai dengan tingkat kebutuhannya yang dalam perkembangannya akan mengalami suatu perubahan. Dalam kehidupan anak ada dua proses yang beroperasi secara kontinu, yaitu pertumbuhan dan perkembangan (Herawati, 2009). Semua orang tua mengharapkan anaknya kelak tumbuh menjadi manusia yang cerdas, bahagia dan memiliki kepribadian yang baik. Orang tua dituntut untuk dapat mengamati perkembangan anak dengan baik dan menerapkan pola asuh yang tetap untuk mewujudkan harapan tersebut (Tedjasaputra, 2001).

Pola asuh demokratis memberikan banyak keuntungan bagi orang tua dan anak. Anak merasa dihargai dengan sikap demokratis orang tua sehingga antara anak dan orangtua terjalin komunikasi yang harmonis. Kerugian, ada kemungkinan anak terlalu berani mengemukakan pendapatnya sehingga ada kesan anak berani dengan orangtua (Kartono, 2000). Pola asuh otoriter memberikan dampak perasaan tertekan pada anak karena diharuskan untuk mengikuti semua aturan orangtua. Keuntungannya, anak dalam sikap dan perilaku sesuai aturan yang diterapkan oleh orang tua (Shochib, 2002).

Keuntungan pola asuh permisif membuat anak menjadi mandiri, tidak bergantung pada orangtua. Disisi lain, kerugiannya adalah anak akan melakukan kebebasan tanpa batas yang merugikan dirinya sendiri atau orangtua. Salah satu peran aktif orang tua adalah mengasuh anak. Pola asuh orang tua merupakan gambaran tentang sikap dan perilaku orang tua dengan anak dalam berinteraksi (Supriyapto,2001). Kemampuan interpersonal dan pengendalian emosional sangat diperlukan orang tua untuk memberikan rasa nyaman pada anak. Sehingga dengan pola asuh yang tepat akan mempengaruhi tingkat kemandirian anak (Ulfah, 2015).

Proses deteksi dan stimulasi tumbuh kembang menjadi hal yang tidak boleh dianggap remeh demi terciptanya generasi penerus yang berkualitas yang mampu tumbuh dan berkembang baik secara fisik, emosisonal, maupun sosial. Stimulasi dini adalah kegiatan merangsang kemampuan dasar anak usia 0-6 tahun agar anak mencapai tumbuh kembang yang optimal sesuai potensi yang dimilikinya. Stimulasi kepada anak hendaknya bervariasi dan ditunjukan terhadap kemampuan dasar anak yaitu: kemampuan gerak kasar, kemampuan gerak halus, kemampuan bicara dan bahasa, kemampuan sosialisasi dan kemandirian, kemampuan kognitif, kreatifitas dan moral-spiritual (Wati, 2016). Kuesioner Pra Skrining Perkembangan atau disebut KPSP merupakan suatu daftar pertanyaan singkat yang ditujukan kepada para orang tua dan dipergunakan sebagai alat untuk melakukan skrining pendahuluan perkembangan anak usia 3 bulan sampai dengan 72 bulan (Prasida, 2015).

Berdasarkan studi pendahuluan yang dilakukan pada tanggal 21 Agustus 2018 di TK GMIM Bukit Moria Malalayang terdapat anak berusia $4-5$ tahun berjumlah 33 orang.Dari hasil wawancara dengan guru, orang tua dan observasi, terdapat 11 anak yang terdiri dari, 5 anak perkembangan motorik halusnya belum bisa memegang pensil dengan baik, belum dapat menulis beberapa hurufdan belum bisa menulis sendiri. Kemudian dari perkembangan sosialisasi dan kemandirian, ada 3 anak yang mampu bersosialisasi dengan baik dan mau bergabung, bermain bersama teman-temannya, serta masih ada 3 anak yang belum mampu mandiri seperti masih di tunggu oleh orang tuanya di TK dan tidak mau di tinggal oleh orang tuanya yang pergi bekerja, tidak mau bergabung dan tidak mau bersosialisasi. Sesuai latar belakang di atas, penulis tertarik melakukan penelitian untuk mengetahui hubungan pola asuh orang tua bekerja dengan perkembangan anak usia prasekolah (4-5 tahun) di TK GMIM Bukit Moria Malalayang. 


\section{METODE PENELITIAN}

Rancangan penelitian ini adalah deskriptif korelasi (descriptive correlation) yaitu bertujan untuk mengungkapkan hubungan korelatif variable, dengan pendekatan cross sectional yaitu suatu penelitian untuk mempelajari dinamika korelasi antara faktor dan resiko dengan efek dengan cara pendekatan, observasi atau pengumpulan data sekaligus pada pada suatu waktu (Point Approach) (Notoatmodjo, 2010).

Sampel merupakan bagian yang diteliti atau sebagaian dari karakteristik yang dimiliki oleh populasi. Sehubungan dengan jumlah populasi yang sedikit, maka teknis sampling yang digunakan adalah sampel jenuh yaitu jumlah populasi yang ada keseluruhannya digunakan sebagai sampel penelitianyang dalam hal ini adalah orang tua bekerja yang memiliki anak bersusia 4-5 tahun di TK GMIM Bukit Moria Malalayang yang berjumlah 33 anak. Penelitian ini dilakukan di TK GMIM Bukit Moria Malalayang pada bulan Agustus - Oktober 2018. Alat yang digunakan dalam penelitian ini adalah kuesioner, yaitu kuesioner pola asuh orang tua dan kuesioner perkembangan anak.

Analisis bivariat untuk mengetahui hubungan antara variable bebas dan variable terikat dengan menggunakan uji statistik spearman rank karena Uji korelasi Spearman adalah uji statistik yang ditujukan untuk mengetahui hubungan antara dua atau lebih variabel berskala Ordinal.Instrument yang digunakan dalam penelitian ini adalah kuesioner, yaitu kuisioner Pra Skrining Perkembangan atau disebut KPSP merupakan suatu daftar pertanyaan singkat yang ditujukan kepada para orang tua dan dipergunakan sebagai alat untuk melakukan skrining pendahuluan perkembangan anak usia 3 bulan sampai dengan 72 bulan (Prasida, 2015). Dan kuisioner pola asuh orang tua yang terdiri atas 36 item pertanyaan dengan pemilihan Skor:

Sangat sering (skor 4), Sering (skor 3), Tidak sering (skor 2), Sangat tidak sering (skor 1 ) dan telah tervalidasi dengan nilai $\alpha 0,021<0,05$.

\section{HASIL dan PEMBAHASAN Karakteristik Responden}

Tabel 1. Distribusi responden berdasarkan umur

\begin{tabular}{ccc}
\hline Umur & $\mathrm{n}$ & $(\%)$ \\
\hline 4 tahun & 10 & 30,3 \\
5 tahun & 23 & 69,7 \\
\hline Total & 33 & 100,0
\end{tabular}

Sumber: Data Primer 2018

Tabel 2. Distribusi responden berdasarkan jenis kelamin

\begin{tabular}{ccc}
\hline Jenis Kelamin & $\mathrm{n}$ & $\%$ \\
\hline Laki - laki & 16 & 48,5 \\
Perempuan & 17 & 51,5 \\
\hline Total & 33 & 100,0
\end{tabular}

Sumber: Data Primer 2018

Tabel 3. Distribusi responden berdasarkan pendidikan ayah

\begin{tabular}{ccc}
\hline Pendidikan Ayah & $\mathrm{n}$ & $(\%)$ \\
\hline SLTP & 1 & 3,0 \\
SLTA & 12 & 36,4 \\
D3/S1 & 15 & 45,5 \\
S-2 & 5 & 15,2 \\
\hline Total & 33 & 100,0
\end{tabular}

Sumber: Data Primer 2018

Tabel 4. Distribusi responden berdasarkan pendidikan ibu

\begin{tabular}{ccc}
\hline Pendidikan Ibu & $\mathrm{n}$ & $\%$ \\
\hline SD & 1 & 3,0 \\
SLTA & 10 & 30,3 \\
D3/S-1 & 19 & 57,6 \\
S-2 & 3 & 9,1 \\
\hline Total & 33 & 100,0
\end{tabular}

Sumber: Data Primer 2018 
Tabel 5. Distribusi responden berdasarkan pekerjaan ayah

\begin{tabular}{ccc}
\hline Pekerjaan Ayah & $\mathrm{n}$ & $\%$ \\
\hline PNS & 11 & 33,3 \\
Pegawai Swasta & 15 & 45,5 \\
Wiraswasta & 5 & 15,2 \\
TNI/POLRI & 2 & 6,1 \\
\hline Total & 33 & 100,0
\end{tabular}

Sumber: Data Primer 2018

Tabel 6. Distribusi responden berdasarkan pekerjaan ibu

\begin{tabular}{ccc}
\hline Pekerjaan Ibu & $\mathrm{n}$ & $\%$ \\
\hline PNS & 9 & 27,3 \\
Pegawai Swasta & 20 & 60,6 \\
Wiraswasta & 4 & 12,1 \\
\hline Total & 33 & 100,0
\end{tabular}

Sumber: Data Primer 2018

Analisis Univariat

Gambaran Pola Asuh Orang Tua Bekerja

Tabel 7. Distribusi pola asuh orang tua bekerja

\begin{tabular}{ccc}
\hline $\begin{array}{c}\text { Pola Asuh Orang } \\
\text { Tua }\end{array}$ & $\mathrm{n}$ & $\%$ \\
\hline Baik & 27 & 81,8 \\
Kurang Baik & 6 & 18,2 \\
\hline Total & 33 & 100,0
\end{tabular}

Sumber: Data Primer 2018

Gambaran Perkembangan Anak

Tabel 8. Distribusi perkembangan anak

\begin{tabular}{ccc}
\hline $\begin{array}{c}\text { Perkembangan } \\
\text { Anak }\end{array}$ & $\mathrm{n}$ & $\%$ \\
\hline Sesuai & 11 & 33,3 \\
Meragukan & 15 & 45,5 \\
Penyimpangan & 7 & 21,2 \\
\hline Total & 33 & 100,0
\end{tabular}

Sumber: Data Primer 2018

\section{Analisis Bivariat}

Tabel 9. Analisis hubungan pola asuh orang tua bekerja dengan perkembangan anak usia prasekolah (4 - 5 Tahun)

\begin{tabular}{|c|c|c|c|c|c|c|c|c|c|}
\hline \multirow{3}{*}{$\begin{array}{c}\text { Pola } \\
\text { Asuh } \\
\text { Orang } \\
\text { Tua } \\
\end{array}$} & \multicolumn{6}{|c|}{ Perkembangan Anak } & \multirow{2}{*}{\multicolumn{2}{|c|}{ Total }} & \multirow{3}{*}{$\begin{array}{c}p \\
\text { value }\end{array}$} \\
\hline & \multicolumn{2}{|c|}{ Sesuai } & \multicolumn{2}{|c|}{$\begin{array}{c}\text { Meraguka } \\
\mathrm{n}\end{array}$} & \multicolumn{2}{|c|}{$\begin{array}{c}\text { Penyimp } \\
\text { angan }\end{array}$} & & & \\
\hline & $\mathrm{n}$ & $\%$ & $\mathrm{n}$ & $\%$ & $\mathrm{n}$ & $\%$ & $\mathrm{n}$ & $\%$ & \\
\hline Baik & 11 & 40,7 & 12 & 44,4 & 4 & 14,8 & 27 & 100 & \multirow[b]{2}{*}{0,021} \\
\hline $\begin{array}{c}\text { Kurang } \\
\text { Baik }\end{array}$ & 0 & 0,0 & 3 & 50,0 & 3 & 50,0 & 6 & 100 & \\
\hline Total & 11 & 33,3 & 15 & 45,5 & 7 & 21,2 & 33 & 100 & \\
\hline
\end{tabular}

Sumber: Data Primer 2018

\section{Pembahasan}

\section{Karakteristik Responden}

Berdasarkan hasil penelitian didapatkan sebagian besar responden berjenis kelamin perempuan sebanyak $51,5 \%$. Jenis kelamin dapat mempengaruhi pola asuh orang tua karena kebanyakan didapati anak perempuan lebih mudah diasuh dari pada anak laki-laki. Dan juga sebagian besar responden berusia 5 tahun ini menunjukkan bahwa sebagian besar responden berada pada usia pra sekolah.

Hasil penelitian ini didapatkan bahwa sebagian besar pendidikan ayah responden terbanyak berpendidikan D3/S1 dan yang paling sedikit berpendidikan SLTP sedangkan pendidikan ibu responden terbanyak berpendidikan D3/S1 dan yang paling sedikit berpendidikan SD. Semakin tinggi pendidikan maka semakin mudah seseorang menerima informasi khususnya informasi tentang cara mengasuh anak dengan baik yang nanti dapat mempengaruhi perkembangan anak (Hurlock, 2006).

Keluarga merupakan unit sosialekonomi terkecil dalam masyarakat. Dalam keluarga, orang tua memegang peranan sebagai pencari nafkah bertanggung jawab memenuhi kebutuhan anak-anaknya dan didapatkan hasil penelitian diperoleh pekerjaan ayah responden terbanyak bekerja sebagai pegawai dan yang paling sedikit bekerja sebagai TNI/POLRI sedangkan pekerjaan ibu responden terbanyak bekerja sebagai pegawai swasta dan yang paling sedikit bekerja sebagai Wiraswasta. 
Analisa Univariat

Gambaran Pola Asuh Orang Tua Bekerja Pada Anak Usia Prasekolah (45 tahun) di TK GMIM Bukit Moria Malalayang.

Hasil penelitian diperoleh gambaran pola asuh orang tua bekerja yang baik sebanyak 27 orang, sedangkan pola asuh orang tua bekerja yang kurang baik sebanyak 6 orang. Hasil penelitian ini sejalan dengan penelitian yang dilakukan oleh Anjani (2006) yang menunjukan bahwa sebanyak $65,5 \%$ orang tua menerapkan pola asuh baik atau demokratis kepada anaknya. Orang tua yang memiliki pendidikan tinggi cenderung menggunakan pola asuh baik dibandingan dengan pola asuh kurang baik. Kondisi ini dipengaruhi oleh pengalaman orang tua yang mengalami pola asuh demokratis sebelumnya, sehingga merekapun menggunakan pola asuh tersebut (Hurlock, 2006).

Kebijakan yang dulu lebih berfokus pada ibu, mulai memberikan kesempatan serta ruang bagi figur ayah untuk mengekspresikan diri dalam proses parenting (pengasuhan), ayah turut memberikan kontribusi penting bagi perkembangan anak, pengalaman yang dialami bersama dengan ayah, akan mempengaruhi seorang anak hingga dewasa nantinya. Peran serta perilaku pengasuhanayah mempengaruhi perkembangan serta kesejahteraan anak dan masa transisi menuju remaja (Cabrera, 2000).

Peran ibu dan ayah dapat memberikan pola pengasuhan yang benar kepada anak-anaknya agar anak dapat tumbuh dan berkembang secara optimal. Orang tua sangat berperan penting dalam kehidupan anak karena orang tua merupakan orang pertama dalam keluarga untuk mendidik, mengasuh, memberikan contoh yang baik agar anak dapat tumbuh dan berkembang secara optimal. Maka disini orang tua dituntut untuk memberikan pola asuh yang tepat dan sesuai untuk usia anaknya.
Tugas keluarga dalam perkembangan anak prasekolah yaitu memenuhi kebutuhan anggota keluarga seperti, kebutuhan tempat tinggal, privasi dan rasa aman, membantu anak untuk bersosialisasi, beradaptasi dengan anak yang baru lahir, sementara kebutuhan anak lain yang lain juga harus terpenuhi, mempertahankan hubungan yang sehat, baik di dalam maupun di luar keluarga, pembagian waktu untuk individu, pasangan dan anak, pembagian tanggung jawab anggota keluarga dan kegiatan dan waktu untuk menstimulasi tumbuh kembang (Friedman, 2010).

Bahasa sangatlah erat kaitannya dengan perkembangan berfikirnya seorang individu. Perkembangan pemikiran individu tampak dalam perkembangan bahasanya. Setiap orang yang berada dalam fase pertumbuhan akan mengalami berbagai hambatan, gangguan serta kesulitan yang pemecahannya kadangkadang memerlukan bantuan orang lain terutama yang profesional. Masalahmasalah yang tidak tertuntaskan secara tepat bisa menimbulkan hambatan dan masalah pada anak masa sekarang, maupun setelah anak melanjutkan ke jenjang sekolah dasar (Hidayat, 2013).

Dampak negatif ibu yang bekerja terhadap perkembangan anak khususnya kurang dalam menstimulasi perkembangan bahasa itu karena kehadiran ibu dalam kehidupan sehari-hari sang anak lebih sedikit dibandingkan dengan ibu yang tidak bekerja, sehingga kesempatan ibu untuk memberikan motivasi dan stimulasi dalam melakukan tugas perkembangan anak terbatas. Namun jika dilihat dari dampak positif ibu yang bekerja terhadap perkembangan anak dapat dilihat apabila anak yang dititipkan ditempat penitipan anak mampu memperkerjakan pengasuh terlatih, maka anak akan memiliki interaksi sosial yang baik, perkembangan kognitif yang pesat dan kecerdasan motorik jika dibandingkan dengan anak yang hanya berada di rumah bersama ibunya yang tidak bekerja (Imaniah, 2013). 


\section{Gambaran Perkembangan Anak Usia Prasekolah (4-5 tahun) di TK GMIM Bukit Moria Malalayang.}

Berdasarkan hasil penelitian diperoleh gambaran perkembangan anak sesuai sebanyak 11 orang, perkembangan anak meragukan sebanyak 15 orang, sedangkan perkembangan anak penyimpangan sebanyak 7 orang. Hal tersebut menunjukkan bahwa sebagian besar tingkat perkembangan anak masih dalam kategori meragukan dengan tahap perkembangannya, akan tetapi tingkat perkembangan sesuai juga masuk dalam kategori cukup untuk perkembangannya.

Anak yang sudah terbiasa menggunakan pakaian sendiri, mampu membedakan warna dan melompat dengan menggunakan satu kaki secara bergantian. Ini berarti anak dapat melakukan tugas perkembangannya dengan baik dan anak berkembang sesuai dengan usianya. Setiap individu berbeda dalam proses tumbuh kembangnya karena di pengaruhi oleh beberapa faktor yaitu faktor herediter, faktor lingkungan (lingkungan pranatal, pengaruh budaya lingkungan, status sosial dan ekonomi keluarga, nutrisi, posisi anak dalam keluarga dapat mempengaruhi sikap orang tua dalam mengasuh dan mendidik anak di lingkungan keluarga) dan faktor internal (kecerdasan, pengaruh hormonal, bahasa dan pengaruh emosi)(Supartini, 2004).

Hasil penelitian menunjukan bahwa sebagian besar perkembangan anak sesuai dengan tahap perkembangannya. Hal ini karena dipengaruhi oleh beberapa faktor diantaranya stimulasi dan pola asuh orang tua. Setiap anak adalah individu yang unik karena faktor bawaan dan lingkungan yang berbeda, maka pencapaian kemampuan perkembangan anak juga berbeda. Jadi, orang tua khususnya ibu mempunyai peranan penting dalam perkembangan anak.

\section{Analisis Bivariat \\ Hubungan Pola Asuh Orang Tua Bekerja Dengan Perkembangan Anak Usia Prasekolah $(4-5$ tahun $)$ di TKGMIM Bukit Moria Malalayang.}

Hasil analisis statistik menggunakan uji spearman rank menunjukan nilai $p=$ 0,021 . Tingkat kemaknaan alfa $(a)$ yang digunakan yaitu 0,05 . Jadi $p=0,021$, lebih kecil dibandingkan nilai $(a) 0,05$ yang menunjukan bahwa terdapat hubungan yang bermakna antara pola asuh orang tua bekerja dengan perkembangan anak usia prasekolah (4-5 tahun). Sesuai hasil penelitian diperoleh sebagian orang tua mempunyai pola asuh orang tua baik, didapatkan hasil perkembangan anak sesuai $(40,7 \%)$, meragukan $(44,4 \%)$ dan menyimpang $(14,8 \%)$, sedangkan pola asuh orang tua kurang baik, didapatkan hasil perkembangan anak sesuai $(0,0 \%)$, meragukan $(50,0 \%)$ dan menyimpang $(50,0 \%)$.

Faktor yang diperoleh oleh peneliti bahwa pola asuh orang tua yang baik masih memiliki perkembangan anak meragukan lebih tinggi (3,7\%) dibandingkan pola asuh orang tua dengan perkembangan anak yang sesuai. Pola asuh yang dijalankan oleh orang tua memberikan pengaruh terhadap pertumbuhan dan perkembangan anak (Walker, 2008). Pola asuh baik merupakan pola asuh yang paling dominan diterapkan orang tua pada penelitian ini.

Penelitian terdahulu oleh Kamilah (2015) di Jatinegara, Jakarta Timurdengan hasil adanya hubungan antara pola asuh dengan perkembangan anak $(p=0,003)$ dengan proporsi pola asuh demokratis sebesar 24,2\%, otoriter $34,7 \%$, dan permisif $41,1 \%$, serta penelitian Rohmawati (2012) yang mendapatkan hasil adanya hubungan antara pola asuh dengan pertumbuhan $(p=0,026)$ dengan proposi pola asuh demokratis sebesar $45,3 \%$, otoriter sebesar 26,4\%, dan permisif sebesar 28,3\%. Hal ini menunjukkan bahwa data yang bervariasi lebih baik dalam menilai hubungan antara 
dua variabel dibandingkan data yang cenderung homogen.

Status pekerjaan seseorang berpengaruh pada partumbuhan dan perkembangan anak. Pada penelitian ini, sebagian besar orang tua anak bekerja. Menurut Heinrich (2014), orang tua yang bekerja penting untuk tetap membangun kebersamaan bersama anak dan orang tua yang bekerja bertujuan penting dalam meningkatkan pertumbuhan dan perkembangan anak. Hal ini berarti pekerjaan orang tua bukan menjadi penghambat dalam mencapai tumbuh kembang anak yang optimal. Dalam penelitian Rokhman (2016), dijelaskan bahwa ibu yang bekerja akan berakibat pada kurangnya waktu kebersamaan antara ibu dan anak. Artinya semakin kurang waktu untuk bersama menyebabkan kesempatan untuk melakukan stimulasi pertumbuhan dan perkembangan pada anak juga berkurang.

Berdasarkan penelitian Pelcovitz (2013) melalui penelitian kohort selama 10 tahun didapatkan data bahwa ibu yang bekerja purna waktu sebelum anak menginjak usia tiga bulan akan bermasalah pada perilakunya seperti cemas dan depresi. Pada ibu yang bekerja paruh waktu sebelum anak berusia satu tahun akan memiliki masalah perilaku yang lebih ringan dibandingkan dengan ibu yang bekerja penuh waktu. Pada penelitian yang sama pada anak berusia empat setengah tahun atau 54 bulan didapatkan bahwa nilai kognitif anak dengan ibu yang bekerja penuh waktu lebih rendah dibandingkan ibu yang tidak bekerja dan tidak ditemukan nilai kognitif yang rendah pada ibu yang bekerja paruh waktu.

Sikap orang tua yang baik menunjukan sikap mempertimbangkan harapan dan pendapat anak secara bersama ketika membuat keputusan, memberikan penghargaan kepada anak atas sikapnya yang baik, menghargai prestasi anak disekolah, mengharapkan anaknya bersikap mandiri diusianya yang tepat, mendukung sikapnya yang konstruktif dan bertanggung jawab, mengkomunikasikan peraturan secara jelas dan langsung, sehingga orang tua yang menggunakan pola asuh baik akan menghasilkan anak yang perkembangannya baik. Sehingga dapat menjadikan anak lebih mengerti dan memahami ketika dilakukan penilaian KPSP (Rahmayanti, 2012).

Pola asuh orang tua yang baik dengan selalu mengepresikan kasih sayang (memeluk, mencium, memberi pujian) melatih emosi dan melakukan pengontrolan pada anak akan berakibat anak merasa diperhatikan dan akan lebih percaya diri, sehingga hal ini akan membentuk pribadi anak yang baik. Hal ini akan sangat berpengaruh terhadap perkembangan anak sejak dini yang meliputi perkembangan personal sosial, bahasa, motorik halus dan motorik kasar. Anak yang merasa diperhatikan dan disayangi oleh orang tuanya tidak ada rasa takut untuk bergaul dengan orang lain, anak lebih berekspresif, kreatif, tidak takut untuk mencoba hal-hal baru sehingga perkembangan anak terutama anak-anak di bawah 5 tahun akan maksimal (Fatimah, 2012).

\section{SIMPULAN}

Berdasarkan hasil penelitian dapat disimpulkan bahwa:

1. Gambaran pola asuh orang tua bekerjapada anak usia prasekolah (4 5 Tahun) di TK GMIM Bukit Moria Malalayang adalah Baik.

2. Gambaran perkembangan anak usia prasekolah (4 - 5 Tahun) di TK GMIM Bukit Moria Malalayang adalah Meragukan.

3. Terdapat hubungan yang signifikan antara pola asuh orang tua bekerjadengan perkembangan anakusia prasekolah (4 - 5 Tahun) di TK GMIM Bukit Moria Malalayang. 
DAFTAR PUSTAKA

Anjani. (2006). Hubungan antara Pola Asuh dengan Masalah Perilaku Sulit makan pada anak TK Aba lempuyangan dan Tk Aisyiyah Miliran. Thesis, Universitas Gadjah Mada.

Cabrera. (2000). Fatherhood in the 21st Century. Child Development, 71, 127136.

Fatimah. (2012). Hubungan Pola Asuh Orang Tua dengan Perkembangan Anak di R.A Darussalam Desa Sumber Mulyo, Jogoroto, Jombang. FIK UNIPDU Jombang.

Friedman. (2010). Buku Ajar Keperawatan Keluarga: Riset , Teori dan Praktek. Jakarta : EGC

Heinrich. (2014). Parent's employment and children's wellbeing. Spring, 24 (1), 121- 146. Doi 10.1542/peds.20112663.

Herawati. (2009). Psikologi Ibu Dan Anak Untuk Kebidanan. Salemba Medika: Jakarta

Hidayat, (2013) Anak. Jakarta: Salemba Medika.

Hurlock. (2006). Perkembangan anak jilid 2. Jakarta: Erlangga.

Imaniah. (2013)Perkembangan usia anak prasekolah pada ibu yang bekerja dan ibu yang tidak bekerja di Desa Serut Kecamatan Panti Kabupaten Jember. Diunduh pada tanggal 15 desember 2018 dari situs /stroge emulated/0/download/ Mifta Dwi Imaniah-0823101010401. Pdf

Kamilah. (2015). Hubungan Pola Asuh dengan Perkembangan Anak Usia 1-3 Tahun di Puskesmas Jatinegara Jakarta Timur. Jurnal Ilmu Keperawatan Indonesia,5 (1), 33-39.

Kartono. (2000). Hygine Mental. Bandung: CV Mandar Maju
Notoatmodjo, S. (2010). Metodologi Penelitian Kesehatan. Rineka Cipta: Jakarta

Pelcovitz, (2013). The impact of working mothers on child development. Klal Perspectives Journal

Prasida,(2015). Pengaruh Penyuluhan Tentang KPSP Terhadap Pengetahuan Guru Di Paud Taman Belia Semarang (Jurnal). The 2nd University Research Coloquium 2015.www.jurnal unimus.ac.id.Diakses Tanggal 10 Desember 2015.

Rahmayanti, (2012). Hubungan Pola Asuh Dengan Perkembangan Anak Usia Prasekolah Di TK Kartika X-9 Cimahi.Jurnal.STIKES Jenderal Achmad Yani Cimahi.

Rohmawati. (2012). Pengaruh tipe pola asuh ibu terhadap pertumbuhan balita di posyandu Srijaya Desa Pucang Miliran Kecamatan Tulung Kabupaten Klaten. Jurnal Involusi Kebidanan, 2 (3), 1-13

Rokhman. (2016). Perbedaan Perkembangan Anak Usia Pra Sekolah (3-6 tahun) Pada Ibu bekerja dan ibu tidak bekerja. Di unduh pada tanggal 15 Desember 2018 dari situs http://jurnal.stikesmuhla.ac.id/wpconte nt/upload/2016/12/72-79AbdulRokhman.pdf

Shochib. (2002). Pola Asuh Orang Tua Dalam Membentu Anak Mengembangkan Disiplin Diri. Rineke Cipta: Jakarta

Supartini. (2004). Buku Ajar Konsep Dasar Keperawatan Anak. EGC: Jakarta.

Supriyapto, (2001). Kumpulan Psikologi Populer. Gramedia pustaka Utama: Jakarta.

Tedjasaputra. (2001). Bermain, Mainan dan Permainan. Grasindo: Jakarta. 
e-journal Keperawatan (e-Kp) Volume 7 No. 18 Februari 2019

Ulfa. (2015). Pengaruh Pola Asuh Orang Tua yang Bekerja Terhadap Perkembangan Kepribadian Remaja. Jakarta.

Walker. (2008). Looking at teacher practices through the lens of parenting style. Journal of Experimental Education, 76, 218-240. Doi: 10.3200/JEXE.76.2.218-240

Wati. (2016). Pengetahuan Guru PAUD Tentang KPSP (Kuesioner Pra Skrining Perkembangan) Sebagai Alat Deteksi Tumbuh Kembang Anak.Jurnal. Varia Pendidikan, Vol. 28, No. 2. Lecturer FKIP PG PAUD Universitas Ahmad Dahlan Yogyakarta. 